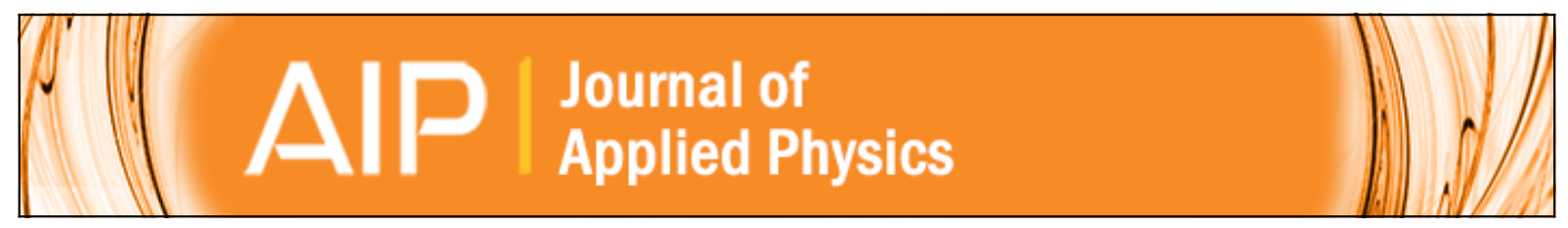

\title{
Creep deformation of a soft magnetic iron-cobalt alloy
}

R. T. Fingers, J. E. Coate, and N. E. Dowling

Citation: Journal of Applied Physics 85, 6037 (1999); doi: 10.1063/1.369074

View online: http://dx.doi.org/10.1063/1.369074

View Table of Contents: http://scitation.aip.org/content/aip/journal/jap/85/8?ver=pdfcov

Published by the AIP Publishing

\section{Articles you may be interested in}

Excellent soft-magnetic properties of (Fe,Co)-Mo-(P,C,B,Si) bulk glassy alloys with ductile deformation behavior Appl. Phys. Lett. 91, 234101 (2007); 10.1063/1.2820608

Large cyclic deformation of a Ni-Mn-Ga shape memory alloy induced by magnetic fields

J. Appl. Phys. 92, 6708 (2002); 10.1063/1.1513875

New Fe-based amorphous alloys with large magnetostriction and wide supercooled liquid region before crystallization

J. Appl. Phys. 85, 4491 (1999); 10.1063/1.370385

Magnetic domains and coercivity in FeCo soft magnetic alloys

J. Appl. Phys. 85, 6034 (1999); 10.1063/1.369073

Soft magnetic properties of LaCo 13 and $\mathrm{La}(\mathrm{Co}, \mathrm{Fe}) 13$ alloys

J. Appl. Phys. 83, 6471 (1998); 10.1063/1.367653

MIT LINCOLN

LABORATORY

CAREERS

Discover the satisfaction of innovation and service

to the nation
- Space Control

- Air \& Missile Defense

- Communications Systems \& Cyber Security

- Intelligence, Surveillance and

Reconnaissance Systems

\section{LINCOLN LABORATORY}

MASSACHUSETTS INSTITUTE OF TECHNOLOGY

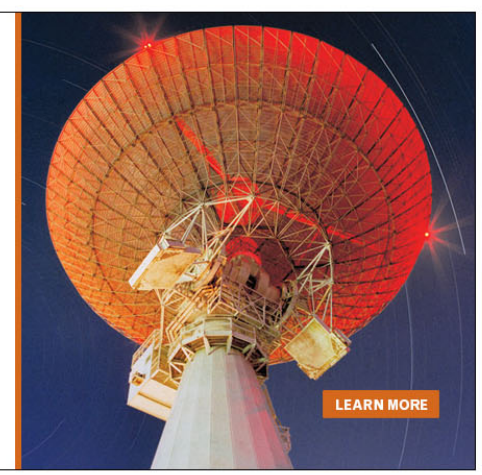




\title{
Creep deformation of a soft magnetic iron-cobalt alloy
}

\author{
R. T. Fingers ${ }^{a)}$ \\ Propulsion Directorate, Air Force Research Laboratory, Wright-Patterson Air Force Base, Ohio 45433
}

J. E. Coate

Materials Directorate, Air Force Research Laboratory, Wright-Patterson Air Force Base, Ohio 45433

\begin{abstract}
N. E. Dowling
Engineering Science and Mechanics Department, Virginia Polytechnic Institute and State University, Blacksburg, Virginia 24061
\end{abstract}

The U.S. Air Force is in the process of developing magnetic bearings, as well as an aircraft integrated power unit and an internal starter/generator for main propulsion engines. These developments are the driving force for the new emphasis on the development of high saturation, low loss magnets capable of maintaining structural integrity in high stress and high temperature environments. It is this combination of desired material characteristics that is the motivation of this effort to measure, model, and predict the creep behavior of such advanced magnetic materials. Hiperco ${ }^{\circledR}$ Alloy 50HS, manufactured by Carpenter Technology Corporation, is one of the leading candidates for these applications. Material specimens were subjected to a battery of mechanical tests in order to study and characterize their behaviors. Tensile tests provided stress versus strain behaviors that clearly indicated: a yield point, a heterogeneous deformation described as Lüders elongation, the Portevin-LeChatelier effect at elevated temperatures, and most often a section of homogeneous deformation that concluded with necking and fracture. Creep testing indicated three distinct types of behavior. Two types resembled a traditional response with primary, secondary, and tertiary stages; while the third type can be characterized by an abrupt increase in strain rate that acts as a transition from one steady-state behavior to another. The relationships between the tensile and creep responses are discussed. Analyses of the mechanical behavior include double linear regression of empirically modeled data, and constant strain rate testing to bridge the tensile and creep test parameters. (c) 1999 American Institute of Physics. [S0021-8979(99)77908-9]

\section{INTRODUCTION}

A national initiative is underway to develop and test a more electric aircraft (MEA) and is being led by the U.S. Air Force Research Laboratory at Wright-Patterson Air Force Base, Ohio. The MEA concept is based on utilizing electric power to drive aircraft subsystems which are currently driven by a combination of hydraulic, pneumatic, electric, and mechanical power transfer systems. ${ }^{1}$ Magnetic bearings, as well as an aircraft integrated power unit and an internal starter/ generator for main propulsion engines are key MEA technologies that will enable an increase in military aircraft reliability, maintainability, and supportability and drastically reduce the need for ground support equipment. These key technologies require a high strength soft magnetic material capable of sustained integrity in a high temperature environment. Iron-cobalt alloys are currently being investigated as part of a magnetic materials characterization effort at the Air Force Research Laboratory. Considering the proposed high temperature and high stress operating environments, a thorough understanding of the mechanical behavior, specifically creep, of the rotor material is essential for the successful design and operation of key MEA technologies. It is the purpose of this article to help provide that understanding and to characterize the tensile and creep behavior in order to establish a reference point for various heat treatments.

\footnotetext{
${ }^{a)}$ Electronic mail: fingerrt@wl.wpafb.af.mil
}

\section{MATERIAL}

The Hiperco ${ }^{\circledR}$ Alloy 50HS (HA50HS) material was manufactured and provided by Carpenter Technology Corporation in rolled sheet $0.015 \mathrm{~cm}$ thick. The alloy is comprised of $48.75 \% \mathrm{Co}, 1.90 \% \mathrm{~V}, 0.30 \% \mathrm{Nb}, 0.05 \% \mathrm{Mn}, 0.05 \% \mathrm{Si}$, $0.01 \% \mathrm{C}$, and a balance of $\mathrm{Fe}$. The HA50HS material is categorized as a near 50-50 iron-cobalt alloy and is classified as having a B2-ordered microstructure. As well as adding vanadium to increase ductility, niobium has been added to act as a grain refining element by inhibiting grain growth during processing and final heat treating; thereby, keeping the grain size relatively small and affecting an increase in strength. $^{2}$

\section{EXPERIMENTAL PROCEDURES}

All of the specimens were electric-discharge machined from the rolled sheets in the $45^{\circ}$ orientation with respect to the rolling direction. The specimens used for creep testing had a $3.18 \mathrm{~cm}$ gage length and a $1.27 \mathrm{~cm}$ gage width, with a gage end blend radius of $1.27 \mathrm{~cm}$. The tensile test specimens were machined with a gage length of $1.59 \mathrm{~cm}$, a gage width of $0.846 \mathrm{~cm}$, and a gage end blend radius of $5.08 \mathrm{~cm}$. The specimens were heat treated at $720^{\circ} \mathrm{C}$ in a dry hydrogen environment. After $1 \mathrm{~h}$ of heating at the load temperature, they were cooled at a rate of approximately $2{ }^{\circ} \mathrm{C}$ per minute down to $600^{\circ} \mathrm{C}$, at which point ordering was no longer a factor and they were cooled to room temperature by opening the furnace. They were then reheated in an air environment 

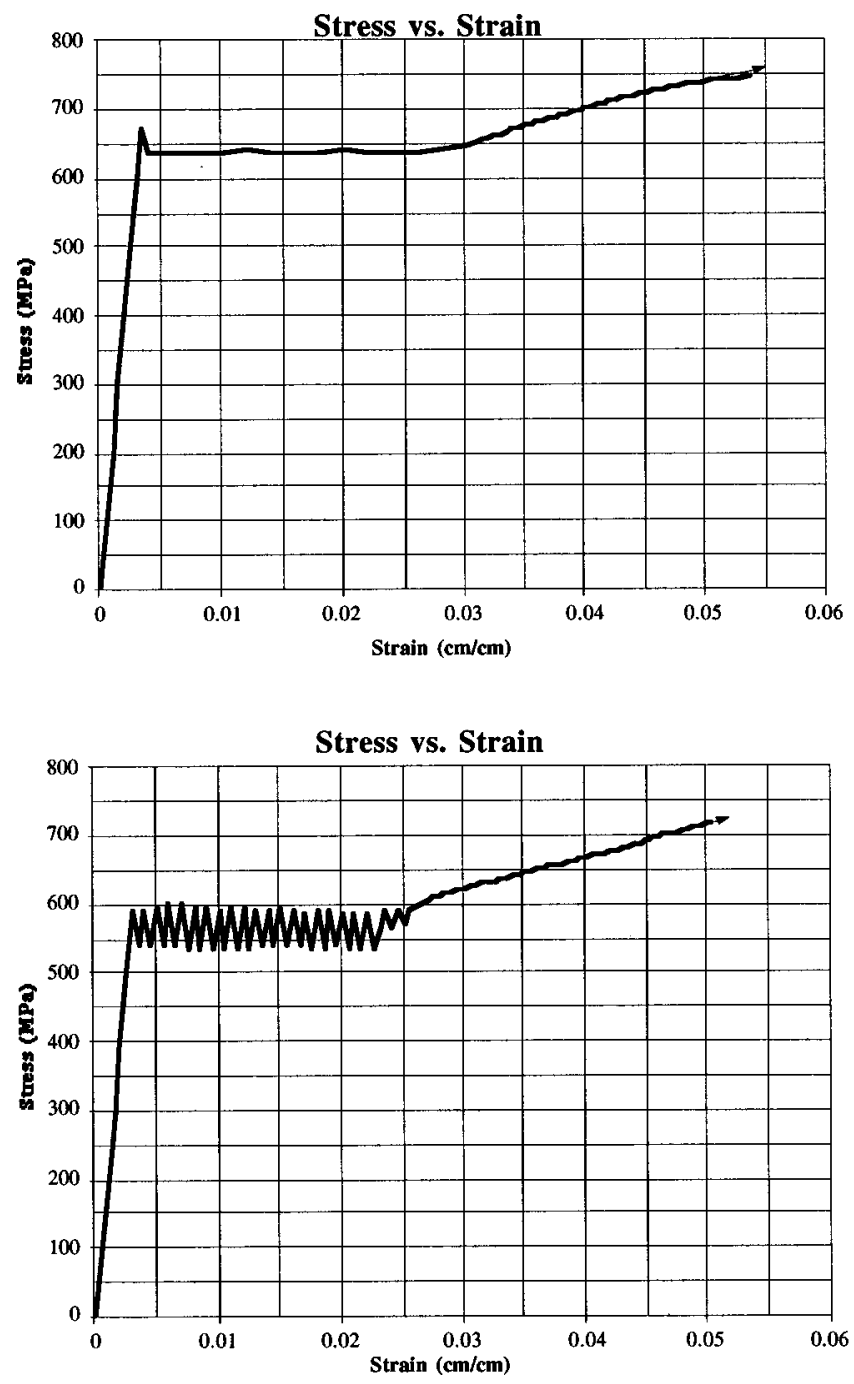

FIG. 1. Typical stress vs strain responses for a HA50HS iron-cobalt alloy tested in the $45^{\circ}$ orientation to the rolling direction at room temperature (top), and at $538^{\circ} \mathrm{C}$ (bottom).

for $45 \mathrm{~min}$ at $400{ }^{\circ} \mathrm{C}$ to generate an electrically insulating oxidation layer. Finally, the specimen edges were hand sanded and examined under an optical microscope to verify acceptable surface and edge conditions.

Tensile testing was performed at temperatures ranging from -54 to $593^{\circ} \mathrm{C}$. The small cross-sectional areas of the specimens required that particular attention be paid to the measuring devices. Uniaxial creep testing was conducted, with constant loads, on SATEC, Model LD, creep rupture testers with a 5:1 lever arm ratio. After proper alignment, displacement versus time data points were recorded electronically.

\section{RESULTS AND DISCUSSION}

48 uniaxial tensile tests were conducted. Due to the yield phenomenon associated with the tensile deformation of this material, it was necessary to document the upper yield point, the lower yield point, and the mid-serration flow stress to fully describe and characterize the deformation response of each test. The upper yield point is defined as the maximum applied stress just prior to the abrupt drop coincident with

\section{Average Strengths Vs. Temperature}

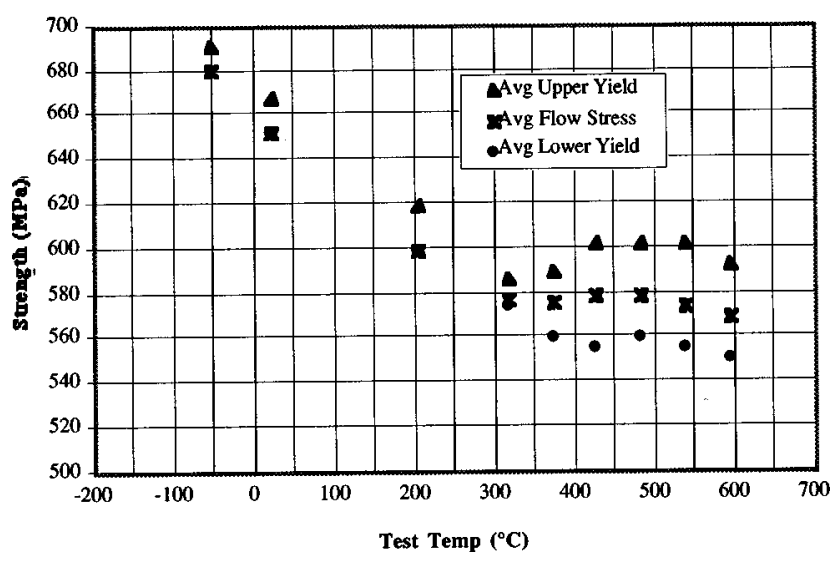

FIG. 2. Average yield strengths of HA50HS specimens tested in the $45^{\circ}$ orientation.

the formation of the first Lüders band. The lower yield point is the level to which the stress falls immediately following the upper yield point. This lower stress level is typically the stress required to propagate the Lüders band along the entire length of the gage section. This single yield point behavior is illustrated in the top plot of Fig. 1. At elevated temperatures, however, the distinct upper and lower yield points are replaced by the serrated stress-strain response that is a characteristic of dynamic strain aging, or the PortevinLeChatelier effect. The average stress value located between the repeated upper and lower points is registered in this study as the mid-serration flow stress. This serrated behavior is illustrated in the bottom plot of Fig. 1.

In the lower regime of the test temperatures, from -54 to $204{ }^{\circ} \mathrm{C}$, there were no serrated flow responses; therefore, the average mid-serration flow stress was recorded as the lower yield stress and was sufficient to propagate the Lüders band through the specimen gage length. As illustrated in Fig. 2 , at $315^{\circ} \mathrm{C}$ the yield point is replaced with serrated flow, which is indicative of dynamic strain aging. At this temperature the average yield point drop is only $2.0 \%$. However, as the single yield point has essentially been eliminated at $371{ }^{\circ} \mathrm{C}$, the magnitude of the repeated drops is approximately $5 \%$. At $427-593{ }^{\circ} \mathrm{C}$ the drops are essentially constant, with a magnitude of about $8 \%$. The fact that the yield stress is independent of temperature in the same temperature range as dynamic strain aging is supported in related literature. ${ }^{3}$ Also, an investigation of long range order of an iron-cobaltvanadium alloy, ${ }^{4}$ revealed a flow stress versus temperature trend very similar to the behavior documented for the HA50HS studied under this research effort.

Following the yield point and Lüders elongation, which was typically represented by a strain of $2 \%-2.5 \%$, the HA50HS material underwent a work hardening process. A maximum ultimate tensile strength of approximately 1000 $\mathrm{MPa}$ is attained at $371^{\circ} \mathrm{C}$. Also, a strain rate sensitivity analysis was conducted with 427 and $482{ }^{\circ} \mathrm{C}$ test data and indicated a sensitivity that was nearly equal to zero. This finding is also supported by related literature pertaining to dynamic strain aging. ${ }^{3}$ 


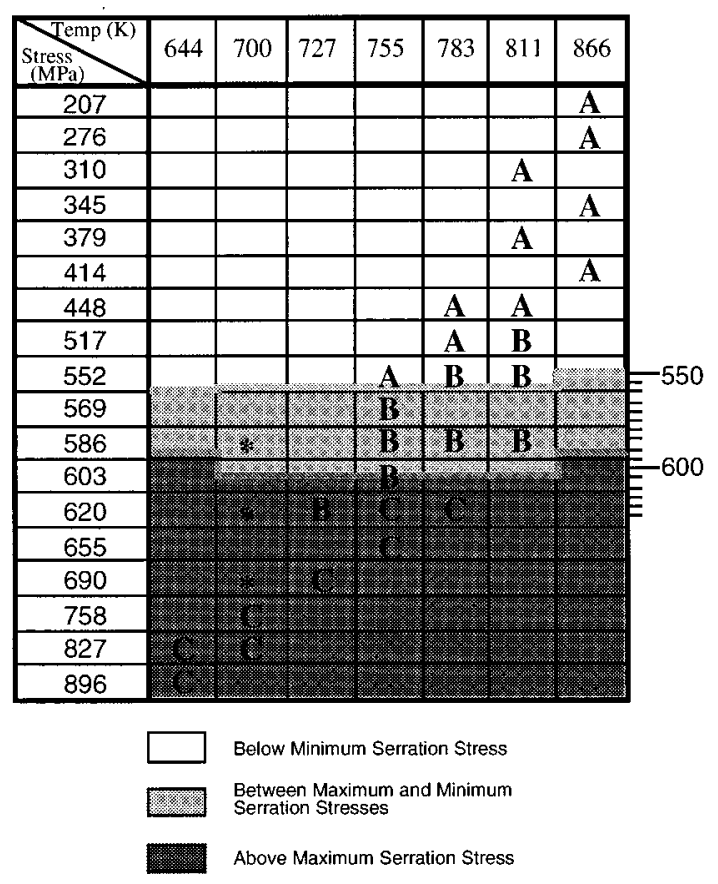
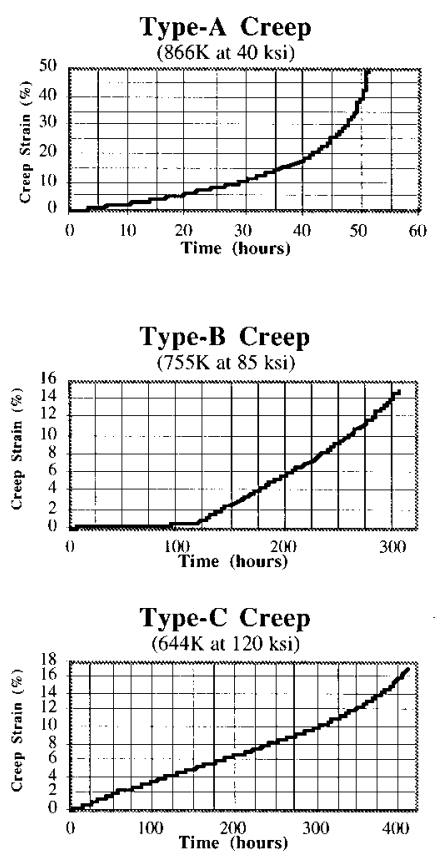

FIG. 3. Creep deformation types of HA50HS specimens subjected to stresses in the proximity of the material's yield strengths.
30 uniaxial creep tests were conducted in this study. Test temperatures ranged from 371 to $593{ }^{\circ} \mathrm{C}$, which correspond to homologous temperatures of 0.36 and 0.49 , respectively. Some of the creep strain versus time responses resembled the traditionally recognized creep curve, ${ }^{5}$ while others could be characterized by an abrupt increase in the steady-state strain rate. Samples of these various creep response types are depicted in Fig. 3. It was concluded that the proximity of the applied stress level to the material yield strength resulted in the various response types. All of the creep testing was done at temperatures within the dynamic strain aging regime. Therefore, an upper and lower or a maximum and minimum serration stress could be determined at each test temperature. If the applied stress in a creep test was between the minimum and maximum serration stresses, then the abrupt increase in the steady-state strain rate would occur. This behavior is identified as B type. Stress levels below the minimum serration stress resulted in a traditional creep curve (A type) while stress levels above the maximum serration stress level resulted in curves similar to the traditional response with little or no primary creep (C type).

Since the three distinct creep strain versus time responses resulted in four separable steady-state regions, all four were modeled. Double linear regression analyses were applied to a modified form of the Arrhenius rate equation, Eq. (1), to determine the governing creep constants. The inverse temperature dependence of the creep strain rate, as incorporated in Eq. (1), is justified based on the effect of vacancy gradients. If an external stress is applied to a polycrystalline material, atom and vacancy motions result, as vacancies are more accommodating along the compressive boundaries and the atoms have a greater propensity toward the tensile boundaries. At lower temperatures this continued transfer of material is maintained primarily by the external loading and causes the grain to deform. At higher tempera- tures, the vacancy gradient tends to even out and become slightly less dependent on the applied stress; hence, a slight inverse proportionality to temperature is predicted. Comparisons of actual test data support the inverse test temperature dependency of steady-state strain rates for diffusional as well as dislocation creep. The relatively low test temperatures, in conjunction with the high applied stresses and the experimentally determined stress exponent, lead to the speculation that the creep mechanism is dislocation glide and climb, and is controlled by climb

$$
\dot{\epsilon}_{\mathrm{SC}}=A \sigma^{n} e^{-(Q / R T)} T^{-1},
$$

where $\dot{\epsilon}_{\mathrm{SC}}$ is the steady-state creep strain rate, $A$ is the kinetic factor, $\sigma$ is the applied stress, $n$ is the stress exponent, $Q$ is the activation energy, $R$ is the universal gas constant, and $T$ is the absolute temperature.

A matrix containing the three steady-state deformation types is illustrated in Fig. 3. The asterisks identify tests that did not result in an obvious type of behavior. The thresholds are determined from the corresponding tensile data. Emphasis is placed on the more likely operating parameters and the A-type behavior is modeled. By modeling the experimentally determined strain rates according to Eq. (1), the kinetic factor, stress exponent, and activation energy were determined to be approximately $9.37 \times 10^{15}\left[\mathrm{~K} /\left(\mathrm{h} \mathrm{MPa}^{n}\right)\right], 3.83$, and $98,851 \mathrm{cal} / \mathrm{mol}$, respectively.

${ }^{1}$ R. E. Quigley, “More electric aircraft,” Conference Record, Proceedings IEEE Applied Power Electronics Conference, March 7-11, 1993, pp. 906-911.

${ }^{2}$ R. T. Fingers and G. Kozlowski, J. Appl. Phys. 81, 4110 (1997).

${ }^{3}$ R. E. Reed-Hill, Physical Metallurgy Principles (Litton Educational, Monterey, CA, 1973).

${ }^{4}$ N. S. Stoloff and R. G. Davies, Prog. Mater. Sci. 13, 1 (1966).

${ }^{5}$ H. J. Frost and M. F. Ashby, Deformation-Mechanism Maps: The Plasticity and Creep of Metals and Ceramics (Pergamon, Elmsford, NY, 1982). 